\title{
REINVENÇÕES DO OLHAR: UM ESTUDO SOBRE O PODER POLÍTICO DA FEIURA
}

\author{
Carolina Felix de Melo (discente) /UFPE \\ Oriana Duarte (orientadora) /UFPE
}

\section{RESUMO}

Este trabalho expõe uma investigação advinda da relação entre o conceito de feiura e a impossibilidade de desvinculá-lo do contexto em que está inserido (ROSENKRANZ, 1853). Muitas vezes, a designação do que é feio ou belo, em uma determinada sociedade, constitui-se através de práticas de manipulação, exercidas por grupos que fabricam, em termos subjetivos e objetivos, os padrões estéticos vigentes, guiando, desse modo, o nosso olhar sobre as coisas (BERGER, 1972). A estética, nesse sentido, emerge como uma ferramenta de poder, capaz de influenciar, por exemplo, ideias, costumes, comportamentos e crenças. Ao questionar a autoridade da acepção do que é belo e, por consequência, o seu lugar subalternizado, no cerne dessa relação de poder, a feiura pode apresentar-se como forma de opor tal hegemonia, funcionando, também, enquanto uma resistência antinorma, um produto que contesta o padrão vigente. Ao estabelecer esse contraponto, o poder político da feiura reside na convocação à reflexão sobre a hegemonia dos padrões estéticos.

Palavras-chave: Feiura; Estética; Política. 


\section{O que é o feio?}

Por mais que se tente, com grandes esforços, minar a relevância da feiura na vida humana, sua presença é perene e inegável, seja na flor murcha no vaso da sala, na fruta podre que impregna a geladeira ou no resíduo de um corpo doente. À vista disso, é inevitável pensar que todos já experienciamos as convenções do feio em nós: um nariz deveras pequeno, ou a orelha grande demais, o espaço entre os dentes etc. Da mesma forma, é crível assumir que, ao longo do ciclo da vida, experienciamos a mutação de inúmeras formas e contornos que, por incontáveis motivos, tornam-se feios ao nosso olhar.

A princípio, nos estudos clássicos sobre o tema, o conceito de feiura se estabelecia como um agregado aos conceitos da beleza, sendo seu oposto ou um erro na tentativa de atingi-la. O filósofo Karl Rosenkranz, ao escrever o livro Aesthetics of Ugliness, em 1853, inaugura o estudo da feiura no campo da estética. Nele ainda se encontra essa relação codependente entre o feio e o belo, porém, começam a ser traçadas outras possibilidades, que viabilizam a emancipação da feiura como objeto de estudo. Doravante, a "estética da feiura deve representar sua origem, suas possibilidades, e seus modos e dessa forma pode ser útil até mesmo para os artistas." (ROSENKRANZ, 2015, p.32).

Em conjunto com outros autores, utilizados nessa pesquisa, como Umberto Eco (2007) e Stephen Bayley (2012), evidencia-se que a feiura possui um caráter mutável, a partir do contexto que está inserida. De fato, a nossa percepção estética é relativa, o que é feio para um, pode ser belo para outro e apesar das diferentes abordagens dos três autores, todos concordam que a feiura, assim como a beleza, é diretamente influenciada pela sua conjuntura. Na qual, até mesmo um ícone imaculado está sujeito a reformulação por seu entorno: "Para alguém pertencente a uma religião não-europeia, poderia parecer desagradável a imagem de um Cristo flagelado, ensanguentado e humilhado, cuja aparente feiura corpórea inspira simpatia e comoção a um cristão" (ECO, 2007, p. 10). Exemplificando, claramente, o potencial poder da estética e do que é associado a ela.

Neste artigo, constrói-se uma investigação atrelada a relação entre o conceito de feiura e a impossibilidade de desvinculá-lo do contexto em que está inserido. Mostrando-se um solo fértil, em especial no campo do design, investigar o poder que essa dinâmica pode exercer socialmente. Enfim, visando atingir o propósito estabelecido, foi realizada uma pesquisa bibliográfica em textos expressivos na área, e em paralelo, uma atividade prática de coleta e análise qualitativa de imagens, possibilitando a investigação aqui apresentada. 


\section{Construindo olhares}

Para entender melhor o motivo da variância de valor estético, entre beleza e feiura, é preciso estabelecer como se forma nossa maneira de ver e compreender as coisas que nos cercam. $\mathrm{O}$ autor de Ways of Seeing, John Berger (1972), que também participou da criação da série documental de mesmo nome exibida na BBC em 1972, fala sobre a importância do contexto em que uma imagem está inserida. Apresentando que tanto o cenário mais abrangente (período histórico, situação econômica, localização geográfica, etc.), como a conjuntura que está mais próximo da imagem em questão (trilha sonora de um filme, enquadramento, disposição, etc.) intervêm na construção do nosso olhar. Os costumes e cultura em que vivemos também se juntam nesse quebra-cabeça de discernimento visual. Isso posto, a percepção que temos das coisas, se dá a partir dessa união, enxergamos através de uma lente de repertórios. Ao anunciar isso, logo no primeiro episódio da série documental, Berger provoca o espectador dizendo: "Eu espero que você considere o que eu organizei aqui, porém seja cético a respeito." (BERGER, 1972). A forma como o próprio John Berger (1972) apresenta o conteúdo, a edição, ordem e disposição, sugestiona a forma como o espectador o apreende, sendo assim, o mesmo adverte: desconfie. Nesse sentido, da mesma forma que uma série documental pode sugestionar nosso olhar, muitos outros aspectos sociais estão sujeitos a essa interferência e dependendo do que se trata, é de vital importância ser cético.

Existem instituições que tentam moldar essa visão, o que o Historiador francês Jacques Rancière denomina "a versão policiada da história" o que significa que somos ordenados a 'circular', não há nada para ver aqui (2001). [...] se a situação é um acidente de trânsito, isso pode ser adequado. Se é uma questão de como nós vemos a história como um todo, então certamente nós devemos estar olhando.' (MIRZOEFF, 2015, p. 16)

Por ser tamanha a abrangência desse fenômeno, podendo influenciar inúmeros aspectos da nossa vivência, a história por exemplo, deve ser observado com lentes de aumento. Dentre esses elementos, inclui-se a forma como nos vemos e como vemos o outro. No livro História da Beleza no Brasil, Denise Bernuzzi (2014) fala como os padrões estéticos mudam no decorrer do tempo, e mais especificamente, como a própria indústria da moda e da beleza são peças chave nessa construção. "Parecia uma anedota de mau gosto: a divulgação do biquíni foi acompanhada pela ampla difusão dos males da celulite. $\mathrm{O}$ amor por si mesmo mal aflorava e já parecia coxo diante daqueles furinhos detestáveis." (SANT'ANNA, 2014, p. 137). Algo, que até então não tinha relevância, torna-se um "problema de saúde" e uma falha estética, devidamente sanados através da compra de cosméticos, serviços, roupas e outros apetrechos destinados a lidar com tal "feiura". Utilizando dos artifícios da propaganda, empresas conseguem direcionar esses ideais de beleza objetivando benefício próprio. 


\section{Experiência de olhar}

Como uma das etapas para o caminhar dessa investigação, foi realizada uma atividade prática de coleta e análise qualitativa de imagens. Com o objetivo de exercitar meu olhar sobre o feio e desenvolver um repertório de feiura mais pessoal, foram coletados 33 casos (dentre objetos de moda, design, arquitetura) categorizados em quatro grupos: belos que permanecem belos; belos que se tornam feios; feios que permanecem feios; e feios que se tornam belos. Essa distribuição foi de vital importância no desenvolver do conhecimento, visto que, para executar essa separação, eu precisei identificar o contexto em que cada caso estava inserido quando surgiu, e, também, investigar se, ao longo do tempo, algo mudou em sua conjuntura para mudar, ou não, a percepção estética do mesmo.

O que a princípio pode parecer um exercício simples, mostra-se um caminho altamente ramificável. Cada exemplo possuía suas particularidades que tornava difícil separá-los categoricamente. Um dos primeiros exemplos que me colocou nessa encruzilhada de conceituação foi o uso de estampa de oncinha na confecção de roupas. Ao se popularizar, pela primeira vez, nos anos 1920 através do uso da própria pele do animal, que se diferenciava de outras peles. O padrão de pintas tinha uma conotação de poder e sensualidade. Em 1967, quando a Primeira-Dama dos EUA, Jackie Kennedy, usou um casaco de pele de leopardo, a conotação de poder e sofisticação do item foi reforçado. 0 que levou, cinco anos depois, aos leopardos da Somália entrarem oficialmente em risco de extinção. Nesse contexto, o movimento contra o uso de peles de animais começou a se fortalecer e o item "original", a pele do animal ganharam uma imagem negativa, chegando a ser estampada na publicação The Encyclopedia of Bad Taste (1990), onde é descrita como brega e ultrapassada. O que parece, no mínimo, peculiar, visto que, o padrão de oncinha continua sendo estampado nos mais diversos materiais e tecidos. Assim, onde se encaixa esse caso? Por conta do impacto ambiental que, de início provocara, seria um belo que se tornara feio? Mas, por meio de outras mídias, seria o belo que continua belo? A meu ver, a última opção. Após se libertar do uso "original", a estampa de oncinha continua sendo amplamente utilizada, tornando-se um clássico da moda. 


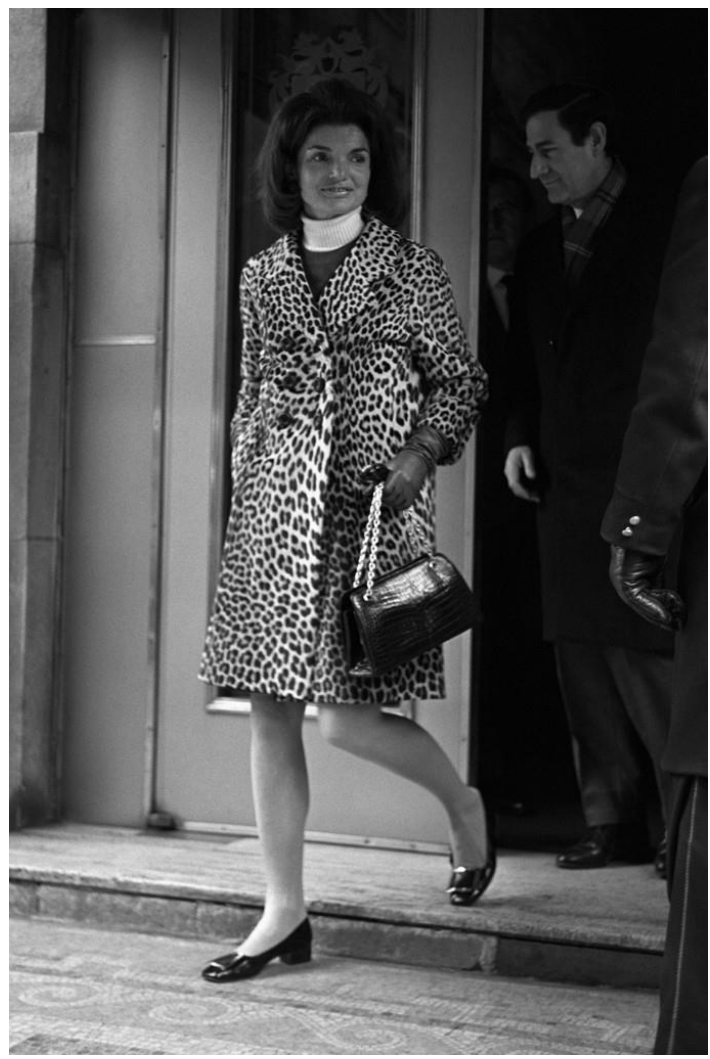

Figura 1. Jackie Kennedy,1967.

Fonte: Traina Sal/WWD Archive.

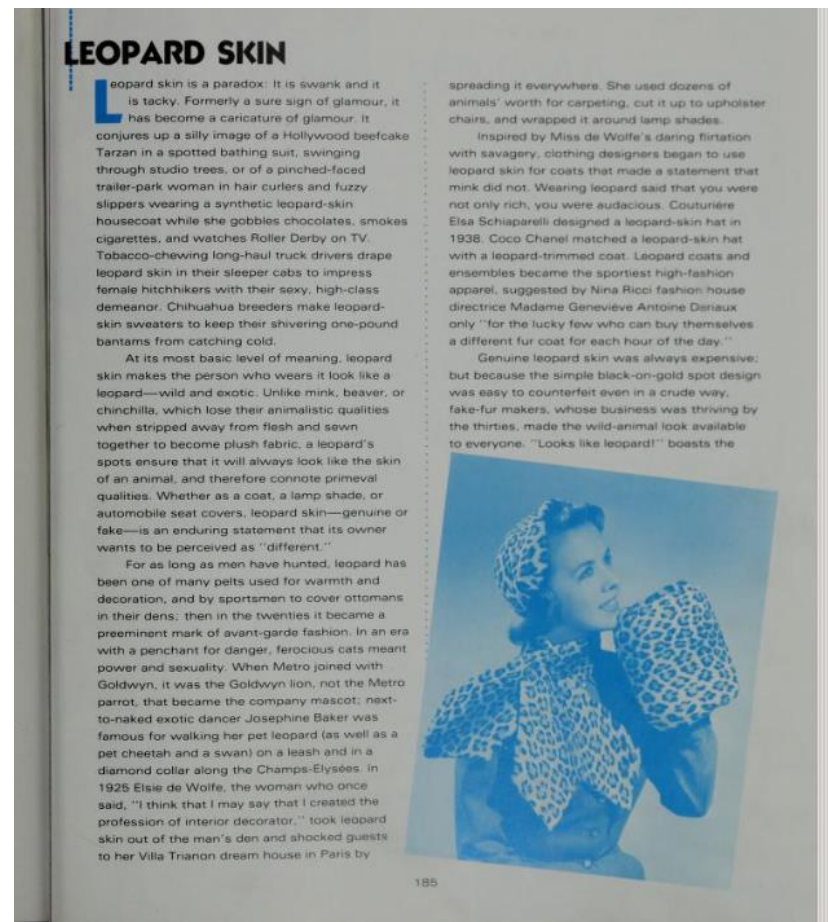

Figura 2. Página 185 da The Encyclopedia of Bad Taste. Fonte: The Encyclopedia of Bad Taste. 


\section{Reinvenção do olhar}

Através do olhar filosófico tradicional, entende-se a feiura como simples oposto da beleza, que surge naturalmente. Essa visão implica que a nossa percepção é única e universal, tirando o peso e a responsabilidade, ao considerar algo como feio. Quando na verdade, a estética tem sido atrelada a valores morais, construindo ideais de comportamento. Pode-se observar tal mecanismo analisando o processo de colonização. O país colonizador se coloca no topo idealizado para justificar uma suposta superioridade. Em seu livro, História da Feiura, Umberto Eco (2007) reserva um momento para falar sobre a Demonização do Inimigo, onde descreve essa manobra:

\footnotetext{
Como sustentáculo para missão civilizadora do homem branco, a representação do africano sempre foi impiedosa, não somente na narrativa e na pintura, mas também nos textos de caráter científico como aqueles de Lombroso. Mas a ideologia do "fardo do homem branco" levou muitas narrativas a criar características repulsivas referentes a qualquer etnia não-europeia, do árabe desleal aos thugs indianos estranguladores, para não falar dos incontáveis chineses de rosto sinistro, mestres de todo tipo de crueldade. (ECO, 2007, p.197)
}

Criar estereótipos de fealdade no inimigo se torna um artifício mais eficiente do que discutir suas diferenças ideológicas. Tal recurso amplamente utilizado ao longo da história, faz-se uma característica comum da feiura, sendo assim, Stephen Bayley (2012) também o aborda em seu livro Ugly, the Aesthetics of Everything, nesse caso, utilizado a Segunda Guerra Mundial como exemplo. Propagandas reforçando ideais e estereótipos através de charges, ilustrações, caricaturas, foram estratégias utilizadas através da feiura para justificar atos de guerra igualmente feios. 


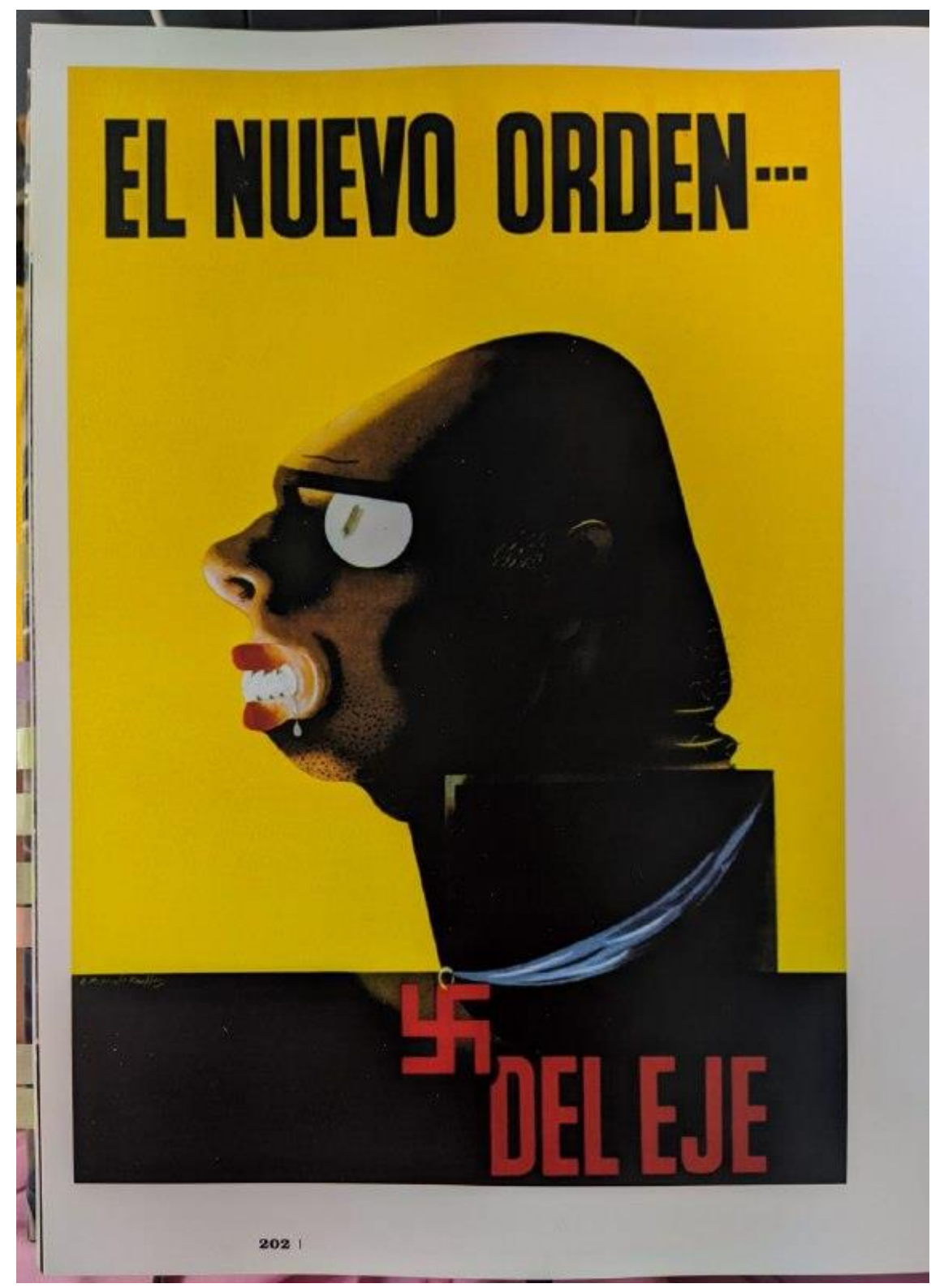

Figura 3. Página 202 do livro Ugly, the Aesthetics of Everything. Fonte: Ugly, the Aesthetics of Everything.

Esse é um dos exemplos que Bayley (2012) apresenta, um cartaz produzido pelo "distinto designer gráfico" Edward McKnight, fruto de uma encomenda realizada pelo Office of Inter-American Affairs, em 1944. A peça gráfica tinha como objetivo atacar o grupo do Eixo, liderado pelos Nazistas, representado pela suástica no pescoço da figura representada. Duas coisas chamaram minha atenção enquanto lia tais páginas do livro, a primeira, que era óbvia no meu olhar, foi ver características estereotípicas de um homem negro vestindo uma suástica. Me indagava o que havia direcionado o designer a tomar tal decisão estética, até que descobri sua nacionalidade, informação que elucidou a questão. E. McKnight era estadunidense. Durante os anos de 1877 até 1965, os Estados Unidos viviam sob leis de segregação racial (Leis de Jim Crow), o racismo institucionalizado, Edward, por sua vez, nasceu e viveu sua vida inteira durante esse período (1890 - 1954). Fica evidente que as escolhas 
do designer não só miravam no inimigo europeu, mas também atingia o inimigo nacional. A segunda coisa que chamou-me a atenção foi perceber que o próprio Stephen Bayley não comenta sobre esse duplo enfeamento do inimigo apresentado no cartaz, inclusive ressaltando a representação de um homem alemão: "Um perfil de cabeça pontiaguda, de óculos e salivante de um alemão sem queixo, cujas particularidades estéticas sabem que profundidade da psique contemporânea”iii (BAYLEY, 2012, p.201). Pergunto-me se a conexão com os estereótipos racistas lhe passou despercebida, ou se simplesmente escolheu não comentar a respeito.

Assim, muitas vezes, a designação do que é feio ou belo, em uma determinada sociedade, constituise através de práticas de manipulação, exercidas por grupos que fabricam, em termos subjetivos e objetivos, os padrões estéticos vigentes, guiando, desse modo, o nosso olhar sobre as coisas. A estética, nesse sentido, emerge como uma ferramenta de poder, capaz de influenciar, por exemplo, ideias, costumes, comportamentos e crenças.

Ao questionar a autoridade da acepção do que é belo e, por consequência, o seu lugar enquanto produto subalternizado, no centro dessa relação de poder, a feiura pode apresentar-se como forma de antagonizar tal hegemonia, funcionando, também, enquanto uma resistência anti-norma, um produto que contesta o padrão vigente. Ao estabelecer esse contraponto, o poder político da feiura pode residir na convocação à reflexão sobre a hegemonia dos padrões estéticos vigentes. Utilizando da feiura contra a feiura. As autoras e organizadoras do livro On the Politics of Uglyness, Sara Rodrigues e Ela Przybylo, apresentam o seguinte exemplo:

\footnotetext{
Mais recentemente e infamemente, Hillary Clinton, no debate final das eleições presidenciais estadunidenses de 2016, foi apelidada por Donald Trump de "mulher nojenta" (um rótulo que pouco depois assumiu os cantos feministas da Internet, resultando, por exemplo, na produção de t-shirts de "mulher nojenta"), demonstrando as formas como as mulheres no poder facilmente se aproximam de vários análogos de fealdade, incluindo a de nojenta.iii (RODRIGUES e PRZYBYLO, 2018, p. 8)
}

Em posse do poder de se fazer visto como o oposto, a feiura se põe em destaque. Conseguinte, parto do pressuposto que acessar a feiura abre caminhos de liberdade e possibilidades de explorar a criatividade, sendo possível alcançar uma vasta pluralidade estética e abandonar amarras sociais e padrões que não nos cabem. Abrindo nossos olhos e nos possibilitando uma escolha mais assertiva e verdadeira daquilo que realmente nos representa ou não.

\section{Referências}

BAYLEY, Stephen. UGLY: The aesthetics of everything. London: Goodman Fiell, 2012. 
BERGER, John. WAYS OF SEEING. London: British Corporation and Penguin Books, 1972.

ECO, Umberto. História da Feiura. Rio de Janeiro: Editora Record, 2007.

MIRZOEFF, Nicholas. How to See the World: An Introduction to Images, from Self-Portraits to Selfies, from Maps to Movies, and More. New York: Basic Books, 2016.

RODRIGUES, Sara e PRZYBYLO, Ela. On the Politics of Ugliness. Cham: Palgrave Macmillan. 2018.

ROSENKRANZ, Karl. Aesthetics of Ugliness. A Critical Edition. Editado e traduzido por Andrei Pop e Mechtild Widrich. Londres, Nova Delhi, Nova York, Sydney: Bloomsbury, 2015.

SANT'ANNA, Denise Bernuzzi de. História da Beleza no Brasil. São Paulo: Editora

Contexto, 2014.

STERN, Jane e Michael, The Encyclopedia of Bad Taste. Nova York: Harper Collins Publishers, 1990.

\footnotetext{
' Tradução própria de: “"There are institutions that try to shape that view, which the French historian Jacques Rancière calls "the police version of history," meaning that we are told to move on, there's nothing to see here (2001). [...] If it is a traffic accident, that may be appropriate. If it is a question of how we see history as a whole, then surely we should be looking." (MIRZOEFF, 2016, p. 16)

ii Tradução própria de: "A pointed-headed, bespectacled, dribbling profile of a chinless German whose aesthetic particulars plumb goodness knows what depths of the contemporary psyche." (BAYLEY, 2012, p.201)

iii Tradução própria de: "Most recently and infamously, Hillary Clinton, in the final debate of the 2016 US presidential election, was dubbed by Donald Trump a "nasty woman" (a label that shortly thereafter took over the feminist corners of the Internet resulting, for instance, in the production of "nasty woman" t-shirts), demonstrating the ways in which women in power easily border on various analogues for ugliness, nastiness included." (RODRIGUES e PRZYBYLO, 2018, p.8)
} 